\title{
Wound Repair: The Fibroblast and the Inhibition of Scar Formation
}

\section{GRIERSON, J. JOSEPH, M. MILLER and J. E. DAY}

\section{London}

The formation of scar tissue in response to damage is the story of the repair cell of connective tissue-the fibroblast (Fig. 1). The quiescent fibroblast or fibrocyte is a cell of low metabolic activity which in the normal situation is virtually inactive. This 'hibernating' cell is found in low numbers throughout connective tissue with its highest density around blood vessels. Following a wound, polymorphs enter the area of damage and clot within a few minutes becoming established in large numbers within hours. One of their principal roles is to digest clot material. Mononuclear cells become established in substantial numbers later; the time is variable but by 48 hours they would be in large numbers in most "normal" wound healing processes. The macrophages phagocytose debris and dying polymorphs. Only after the cleaning up process is well established do fibroblasts become prominent. Pharmacological control of the fibroblast depends on an understanding of the processes of importance in its life history at the wound site. For the purpose of this presentation the stages in the life history of the fibroblast during tissue repair have been divided into

(a) stimulation and migration;

(b) division;

(c) contraction;

(d) synthesis of the extracellular matrix.

Of course, these processes often occur concurrently at the wound site but it is convenient to treat them separately.

\section{Stimulation and Migration}

The fibrocyte, on activation into a fibroblast, is stimulated via its surface membrane receptor system to migrate. Migratory stimuli are classified into three main types; haptotactic, chemokinetic and chemotactic.

Haptotaxis is the directional movement of cells along a solid which has become impregnated with an attractant. If cultured scleral fibroblasts are seeded down onto a flask or petri dish which has been coated with strands of vitreal (Type 2) collagen, initially the settlement is random. Within a few hours fibroblasts become preferentially aggregated along the collagen strands (Fig. 2). Time lapse cinephotomicrography shows that the fibroblasts migrate along the strands, more or less in the same direction. The fibroblasts, as they move, lay down a trail of glycoprotein attractants which stimulate other fibroblasts to follow the same path thus establishing a "track of preference". ${ }^{1}$

If skin fibroblasts are injected into the rabbit vitreous, the same process can be seen to take place in vivo with fibroblasts migrating along the collapsed vitreal gel towards the optic nerve head or the ora serrata. ${ }^{2}$

Chemokinetic stimuli induce fibroblasts to migrate but not in a directional manner whereas chemotactic stimuli cause fibroblasts to migrate down a concentration gradient. These substances are usually in solution or in suspension and their chemoattraction can be measured in vitro in a variety of ways, one of which is the Boyden chamber. ${ }^{3}$ In the Boyden chamber or modified Boyden, the stimulant is placed on one side of a porous membrane and fibroblasts are placed on the other. The pores are large enough for the fibroblasts to pass through from one side to the other. A positive chemoattractant induces significantly more fibroblasts to traverse the membrane than a control solution. Figure 3 shows the dose response curve for a solution of fibronectin. 

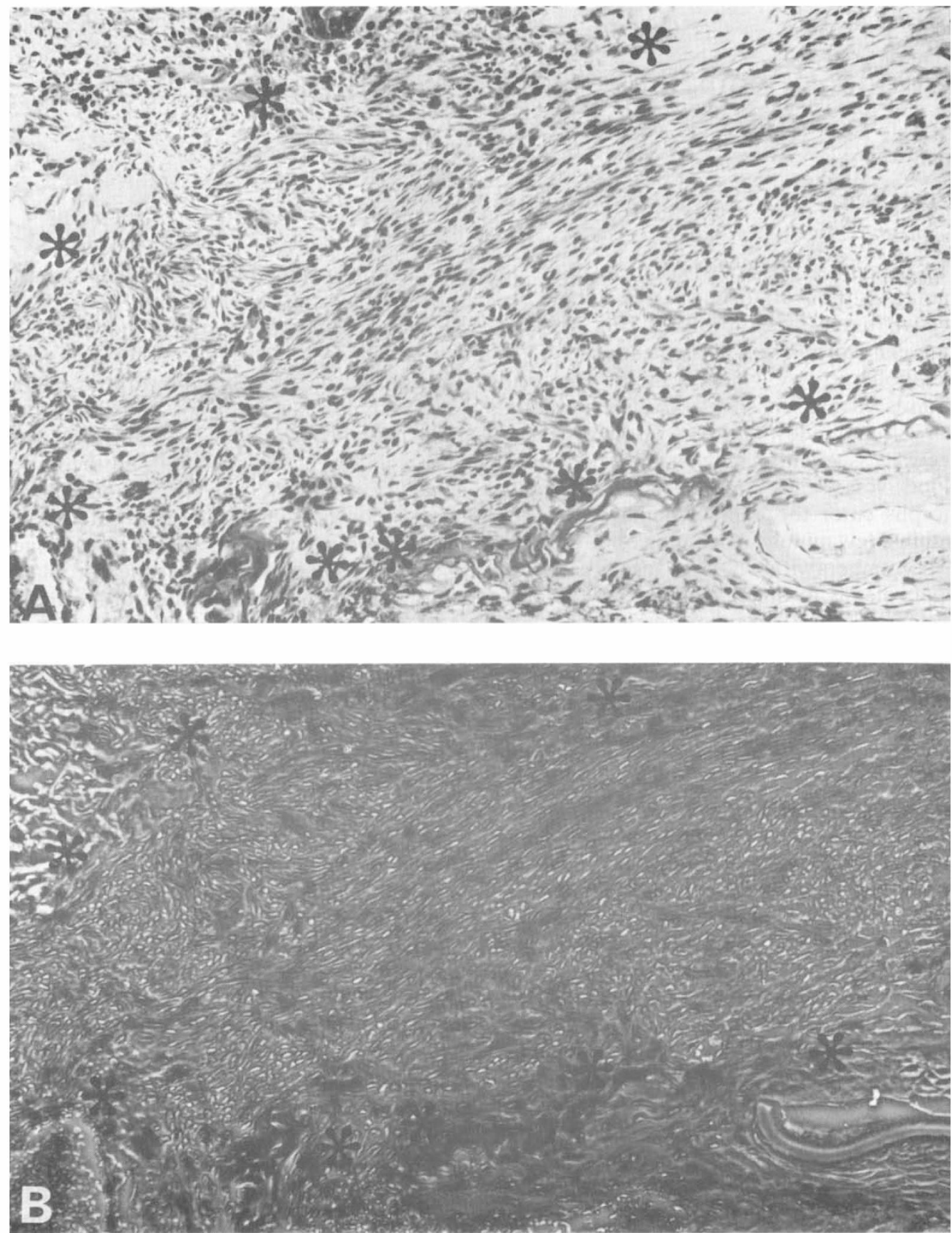

Fig. 1. Scar tissue at the limbal region of the rabbit eye following experimental drainage surgery. The scar tissue is outlined by asterisks. (a) By conventional light microscopy the cellular constituents of the scar can be seen; in particular the elongated spindle shaped fibroblasts. (b) By phase microscopy the collagenous extracellular component of the scar can be appreciated (14 day wound; $\times 800)$. 


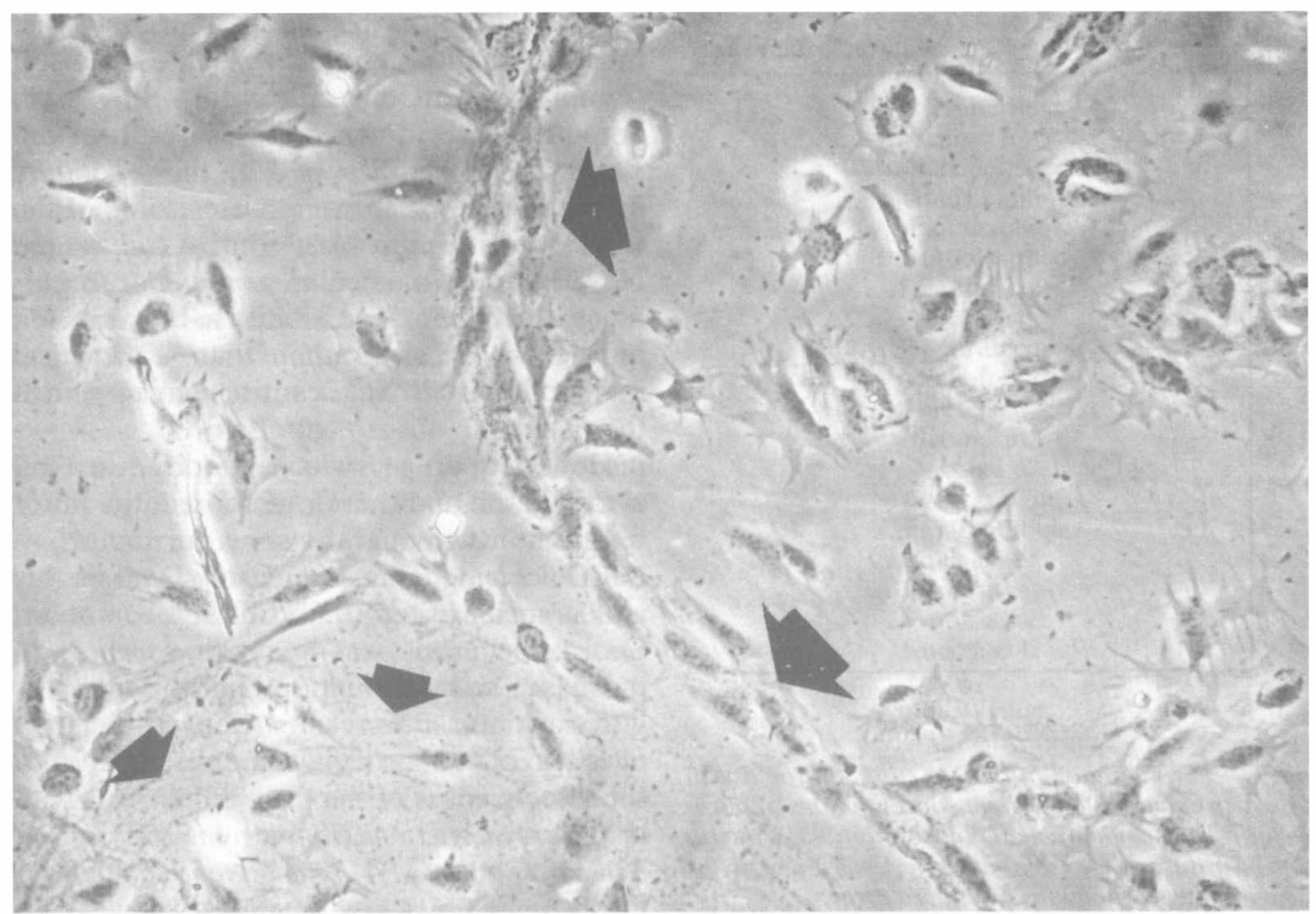

Fig. 2. Settlement of bovine scleral fibroblasts on a flask which has been "streaked" with condensed fibronectin. Fibronectin strands can be seen in one corner of the phase contrast micrograph (small arrows). Fibroblasts can be seen aggregated on a particularly large fibronectin strand (large arrows). These fibroblasts are elongated and timelapse shows the cells moving in a unidirectional manner $(\times 500)$.

Fibronectin is produced in both soluble and insoluble forms at the site of wound healing by several cell types including fibroblasts. To determine whether we are dealing with chemokinesis or chemotaxis a chequerboard analysis is needed ${ }^{4}$ An array is established so that there are different concentrations of attractant on both sides of the membrane. Chemokinesis is shown by the diagonal across the chequerboard where concentrations of the attractant are the same on either side of the membrane. Chemotaxis requires the attractant to be on the opposite side of the membrane from the cells i.e. the first vertical column (Fig. 4). It can be seen (Fig. 4) that a solution of fibronectin is chemotactic for Tenon's fibroblasts but also there is some chemokinesis. Substances like serum albumins are thought to be chemokinetic without having any appreciable chemotaxis. The list of chemoattractants for fibroblasts is extensive, being currently around twenty and getting larger all the time. ${ }^{5}$ In addition to fibronectin other chemotactic factors include collagen fragments. fragments of elastin. platelet derived growth factor, interleukins. leukotriene, the C5a of the complement cascade. fibroblast conditioned medium. epithelial conditioned medium and even ATP. As can be appreciated, they are for the most part products of damaged tissue. substances which would be produced by proliferating cells at the site of a wound or the products of inflammatory mononuclear cells. It was once thought that polymorphs were responsible for attracting fibroblasts into a wound but lymphocytes and, particularly, macrophages are now considered to release fibroblast chemoattractants. In some circumstances, macrophages can have the opposite effect by releasing inhibitors of fibroblast migration. ${ }^{6}$

Theoretically, there are three main approaches to the control of fibroblast activation and migration. The first is to eliminate, or at least to dampen, the stimuli which promote migration. The second is to neutralise the 


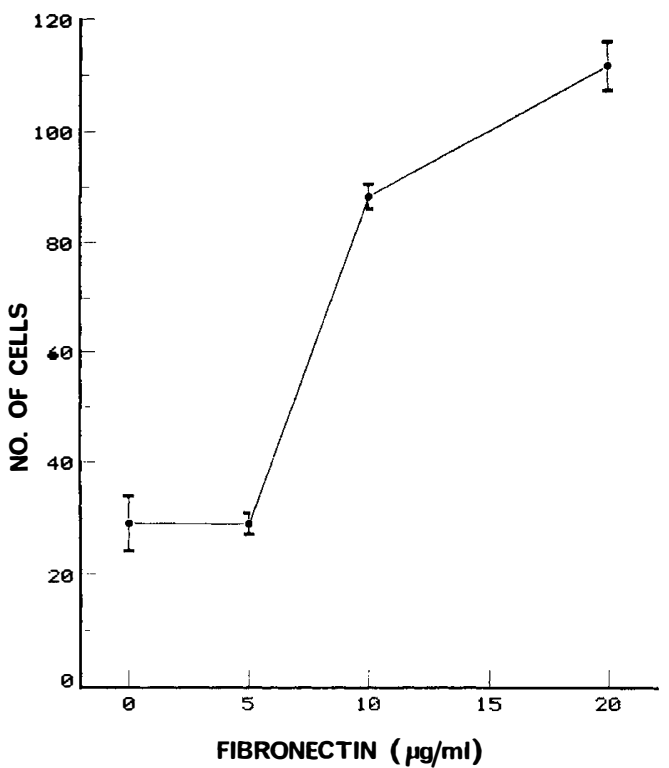

Fig. 3. The migration of rabbit Tenon's fibroblasts in a Boyden chamber to different concentrations of fibronectin. The chemoattractant induces fibroblasts migration in a dose responsive manner. Each point is the mean of 3 determinations \pm standard error.

receptor system on the surface membrane of the fibroblasts so that the chemoattractant signals fail to elicit a response. While the third is to compromise the locomotory system of the fibroblast so that even although there are signals present and the signals can get through, the cells are too sluggish to respond.

Obviously, anti-inflammatory drugs such as corticosteroids will help to reduce the chemoattractant stimuli at the wound site because they will reduce the influx of inflammatory cells into the wound and macrophages and lymphocytes produce potent chemoattractants for fibroblasts. Chemicals which can neutralise chemoattractants include such unlikely materiais as actin. Actin has an avid affinity for fibronectin which is produced in copious amounts in and around a wound. When actin binds to fibronectin it impairs the chemotactic, chemokinetic and haptotactic activity of the latter. This is not just a test-tube phenomenon because injections of actin at a site of injury have been shown to impede seriously the normal fibroblastic response.

There are, undoubtedly, receptors on the surface of fibroblasts through which the signals for enhanced migration function. Total or specific receptor blockade represents an intriguing and potentially valuable means of fibroblast control. Receptor blockade, because it does not necessarily result in cell death, is not handicapped by the secondary inflammation which complicates some of the other forms of fibroblast control (see later). However, in an ocular context, receptor blockade remains a possibility to be evaluated in the laboratory rather than a practical method for modifying scar tissue formation in the patient.

However drugs, which modify the cell cytoskeleton and therefore depress the fibroblast's ability to migrate, show current promise. Colchicine inhibits microtubule assembly and as such can retard fibroblast locomotion. Oral colchicine was recently shown to decrease scar formation in the rabbit's vitreous $^{7}$ and the results were sufficiently encouraging to justify a trial investigation of the effectiveness of the drug on patients with proliferative vitreoretinopathy (PVR).

UPPER CHAMBERS

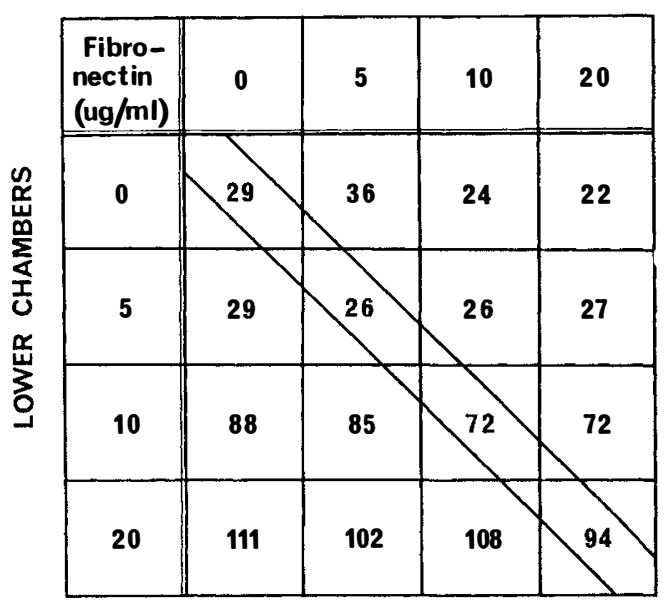

Fig. 4. A chequerboard of the migration of rabbit Tenon's fibroblasts in a Boyden chamber. Cells and different concentrations of fibronectin are placed in the upper wells. Different concentrations of fibronectin are placed in the lower wells. The fibroblasts are given the opportunity to migrate from the upper to lower wells through a permeable membrane. It can be seen that the fibroblasts migrate both to a concentration gradient (vertical column one, where there is fibronectin in the lower well but not in the upper) i.e. chemotaxis and in the absence of a gradient (diagonal where the concentration of fibronectin is equal in both chambers) i.e. chemokinesis. 


\section{Division}

It is a little fatuous to separate migration and division into separate categories. Proliferation can be considered to be the combined effects of migration and division and, for that matter, most growth factors not only promote mitosis but are also chemotactic. Exogenous growth factors regulate the division cycle of fibroblasts. Some stimulate the fibrocyte to come out of its G0 stage while others exert their influence at the G1 stage prior to DNA synthesis. Growth factors do not seem to influence the division cycle thereafter from DNA synthesis (S) through G1 into mitosis (M) but on returning to G1, growth factors are required to push the cell through the division cycle once again. It is not clear where and how all the various growth promoting substances exert their effect on the fibroblast cycle, but platelet derived growth factor activates protooncogenes (genes which control growth) in the fibroblast as it emerges from quiescence and epidermal growth factor decreases the time the cell spends in $\mathrm{G} 1 .^{8}$ On the other side of the coin, some prostaglandins can down regulate fibroblast growth, the inhibition being related to increased amounts of intracellular cyclic AMP and, in addition, interferon has an antiproliferative effect by prolonging the time the fibroblast spends in G0/G1 and G2. ${ }^{9}$

Fibroblasts are relatively late arrivals at the site of a wound, they reach optimal numbers within one to two weeks, ${ }^{10}$ plateau and then slowly decrease in numbers over a protracted period extending up to several months. ${ }^{11}$ Table I shows a list of medications which have been used to control fibroblast numbers in scar tissue formation. It is by no means comprehensive but each of the drugs listed has been used in an ocular context either in clinical or experimental studies. Mononuclear cells are a major source of growth promoting and inhibiting substances which are effective on fibroblasts. Therefore steroids which dampen down the inflammation reduce the amount of 'stimulator' at the wound and retard fibroblast growth. There is good in vitro evidence that corticosteroids have a direct influence on fibroblast proliferation and suppress their normal growth curve on the culture plate. ${ }^{12}$ Elevated histamine levels in culture
Table I Some classes of drugs which have been used to control fibroblast proliferation in an ocular context

Corticosteroids
Prednisolone
Dexamethasone
Triamcinolone
Antimetabolites
5-Fluorouracil
Daunomycin
Adriamycin
Doxorubicin
Methotrexate
Thiotepa
Bleomycin
Cytosine arabinoside
Anthracycline
Antimicrotubules
Colchicine
Vincristine
Vinblastine
Nocodazole
Taxol
Antihistamine
Diphenhydramine

produce a several hundred per cent increase in fibroblast numbers over control values. Interestingly, antihistamines (diphenhydramine) can suppress the stimulated fibroblast growth curves and these compounds may, potentially, serve as useful fibroblast modulators in the clinical situation. ${ }^{13}$

Of the various antimetabolites, 5-fluorouracil has been popular in an ocular context to decrease the numbers of fibroblasts within scar tissue. 5-fluorouracil is a synthetic pyrimidine which inhibits the formation of thymidine and so has its maximal influence on DNA synthesis (S phase) but also has some effect on RNA synthesis. Gressel et al. ${ }^{14}$ and Kay and co-workers ${ }^{15}$ have used 5-fluorouracil to control scar formation following experimental aqueous drainage surgery. Following the success of experimental studies, Heuer et al. ${ }^{16}$ have used the drug in a pilot study to prevent fibrous collapse of drainage blebs in patients with a poor drainage surgical prognosis. Both experimental ${ }^{17}$ and clinical ${ }^{18}$ evidence suggests that antineoplastic agents like 5-fluorouracil can reduce the amount of fibrous reproliferation in the vitreous following vitrectomy procedures for the treatment of complex retinal detachment.

The antibiotic daunomycin has been used as 
an antitumour agent because it binds and blocks DNA function and also causes chain scission through generation of free radicals in the immediate vicinity of the DNA molecule. Inhibition of fibroblast growth with this antineoplastic agent has been shown within the eye $^{19}$ and in the culture flask. ${ }^{20}$

The vinca alkaloids like colchicine not only inhibit fibroblast locomotion (see previous section) but also arrest the cell division cycle by their well known action on the microtubules of the metaphase spindle. Without an intact spindle the chromosomes are dispersed in the cytoplasm which ultimately leads to cell death.

The disadvantage of many of the drugs listed in Table I, is their general tissue toxicity which is quite a problem for scar tissue control in and around such a delicate and vulnerable structure as the eye. For some time now, research in one area of tumour cell killing has centred on the magic bullet principle in an attempt to introduce selectivity. The idea is to target drugs down onto the specific cell to be killed while leaving others untouched and in this way far lower concentrations of cytocidal agents are needed (Table II). The targeting

Table II Selective targeting agents can be linked with cell killing 'bullets' to destroy fibroblasts in scar tissue

\begin{tabular}{ll}
$\begin{array}{l}\text { Targeting } \\
\text { Bullets } \\
\text { Polyclonal antibodies } \\
\text { Monoclonal antibodies }\end{array}$ & Ricin \\
Lectins & Diphtheria toxin \\
Mannolonin & Abrin \\
\cline { 2 - 2 } & Daunomycin \\
& Daunomycin +acid \\
sensitive carrier & Adriamycin \\
& Methotrexate \\
& Complement \\
\hline
\end{tabular}

vehicle can be anything which is specific to the surface membrane of the cell to be killed and, of course, does not present itself to other adjacent cells. Lectins can be used for example but by far the most common targeting agents are antibodies. Antibiotics like adriamycin and daunomycin have been conjugated to mono- clonal antibodies and targeted to tumour cells but problems due to loss of effectiveness following linkage to the antibody have arisen. Recently some of the problem has been overcome by introducing an acid sensitive spacer between the antibody and the antibiotic. ${ }^{21}$ The spacer is unaffected by normal $\mathrm{pH}$ outside the cell but when internalised into the target cell the low pH of the lysosomal system cleaves the spacer molecule and the antibiotic 'bullet' is released to do its work.

Perhaps the most popular 'bullet' is ricin, partly because it takes only one molecule to kill a cell and partly because of its molecular structure. The ricin molecule consists of two polypeptides; one is the active killing arm and the other adheres to cell surfaces. If the nonspecific adhering polypeptide is replaced by the selective antibody then the killing arm can be targeted selectively to the cell of choice. ${ }^{22}$

Several alternative molecular combinations have been studied involving ricin, parts of the ricin molecule and other toxins.

Selective killing of fibroblasts, the subjects of this presentation, is in its infancy but may be an important future development for the control of ocular scarring. Fibroblasts have been selectively killed in vitro, usually as a tissue culture device to rid the culture of fibroblasts and so preserve another less vigorous cell type. We have illustrated the mechanism with two examples from our laboratory where polyclonal antibodies have been used to target and complement has been used as the bullet (Fig. 5). In the first example (Fig. 5a) the test cultures have been treated with antifibronectin antibodies and complement. As we know, fibroblasts produce copious amounts of fibronectin and some of the fibronectin links intimately with the cell membrane. Therefore some of the antibody to fibronectin will be at the fibroblast cell surface and the fibroblasts are vulnerable to complement lysis. It can be seen that the killing is inefficient because, although the cells do not thrive when compared to a normal growth curve, it still takes 7 days to eliminate the fibroblast population. In Fig. 5b we have used a polyclonal antibody to fibroblast cell membrane which is considerably more effective, there being virtually no cells left after 1.5 days exposure to the antibody and complement. 


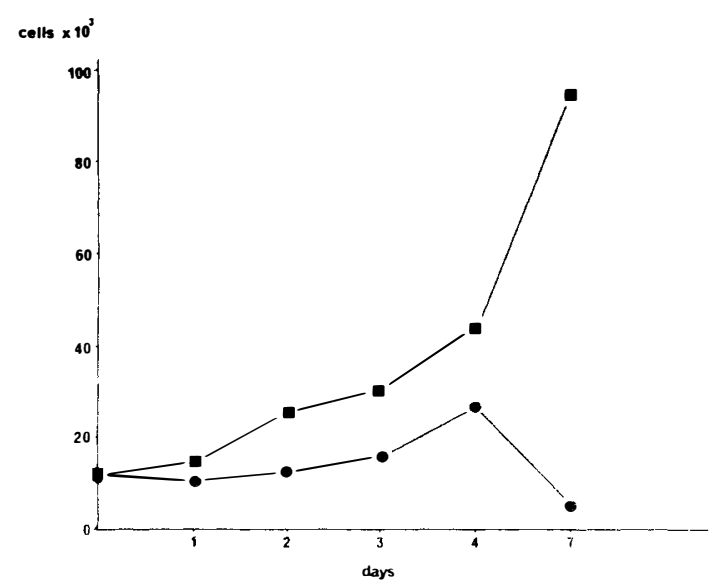

A

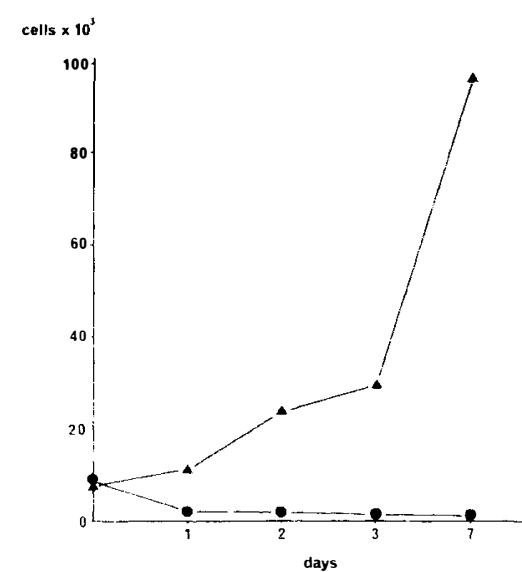

B

Fig. 5. Rabbit skin fibroblasts were settled at $1 \times 10^{4}$ cells per culture chamber. (a) The squares show the normal growth curve. The circles show that in the presence of antifibronectin antibodies (polyclonal) and complement the fibroblasts fail to thrive. (b) The triangles show the normal growth curve whereas the circles show that the fibroblast population is virtually lost one day later when exposed to a polyclonal antifibroblast surface membrane antibody and complement.

\section{Contraction}

At one time it was considered that the contraction which resulted in the closure of a gaping wound was brought about by the shortening of collagen. It is true that collagen shrinkage can take place in the test tube but this is at nonphysiologically high temperatures. It is now considered that wound contraction is a cellular rather than an extracellular event; the cell responsible for the generation of the contractile force being the fibroblast. ${ }^{23}$

Gabbiani and colleagues put forward the concept of the 'myofibroblast' as the contractile stage in the life history of the fibroblast in a wound or in granulation tissue. Their idea was that fibroblasts which looked something like smooth muscle cells also became lined up and acted like muscle cells to contract scar tissue and bring about wound closure..$^{23.24} \mathrm{On}$ the face of it their evidence was reasonable. Among the evidence put forward was that the electron microscopic features of some fibroblasts were not that of cells with abundant rough endoplasmic reticulum in their cytoplasm (Fig. 6a and b) but, instead, they were elongated, had indented nuclei and they had aggregates of cytoplasmic action microfilaments (Fig. 6c and d). These elongated spindle shaped cells were defined as myofibroblasts. In addition, immunofluorescent staining showed cells with abundant smooth muscle elements in early wounds and biochemically substantial amounts of actin were isolated from wounds and granulation tissue when they were known to be at a contractile stage of scar tissue development. Perhaps one of the most interesting pieces of evidence was that strips of granulation tissue were responsive to pharmacological manipulation in an organ bath in much the same way that was done routinely with strips of smooth muscle tissue (see later).

The case for fibroblast activity being responsible for the contraction of scars is not in doubt but the concept of the fibroblast being or even acting as a smooth muscle cell may not be correct. It is thought more likely that wound closure and contraction of granulation tissue is brought about by the migration of fibroblasts into the injury site. Fibroblasts, when they migrate, in contrast to other mobile cells e.g. macrophages, generate extremely strong tractional forces in the substrate on which they move. A remarkable demonstration of these forces was shown by Harris who grew fibroblasts and other cells on gossamer sheets of silicone. These extremely 

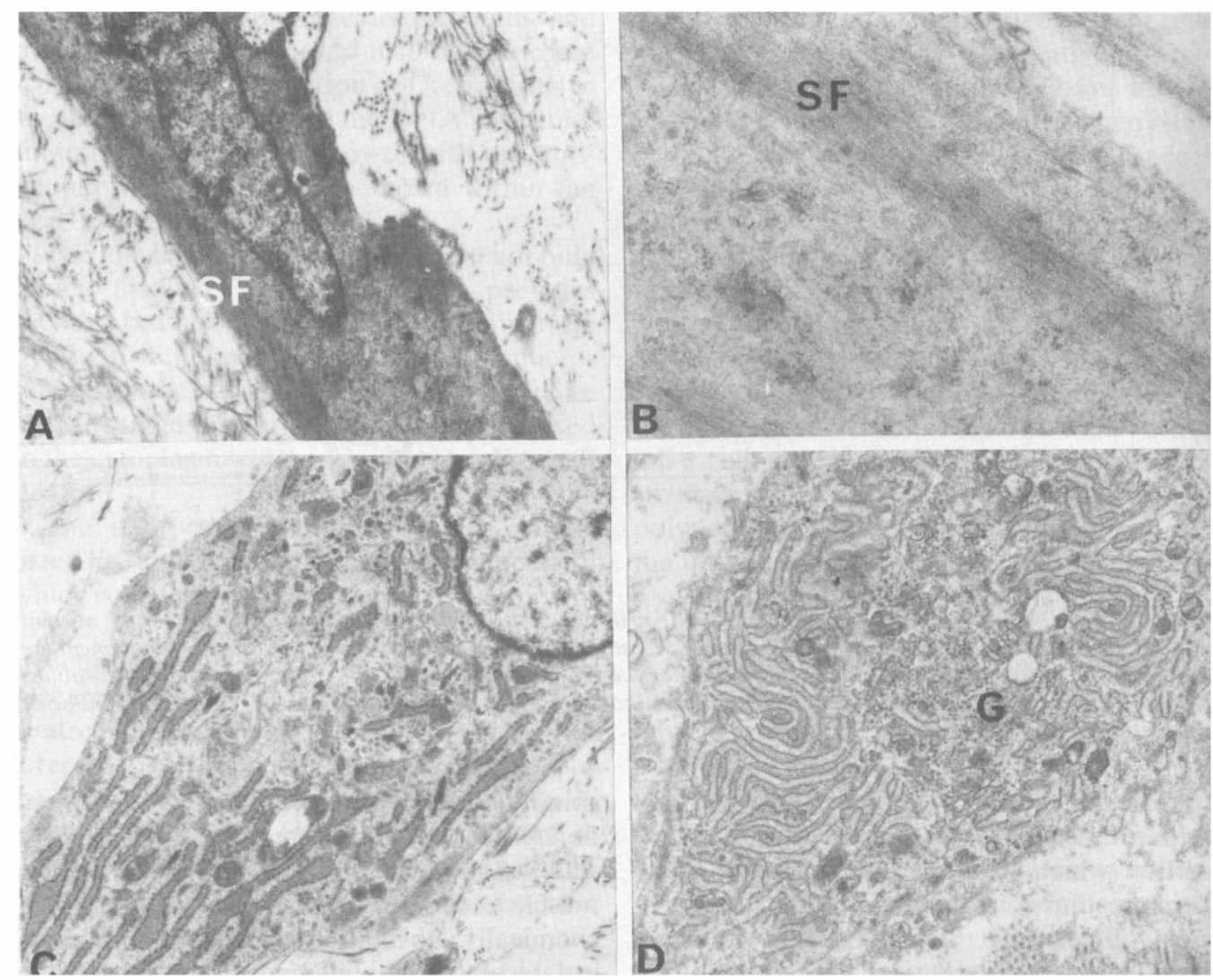

Fig. 6. Transmission electron micrographs of fibroblasts from ocular scar tissue. (a) A fibroblast with myofibroblast characteristics. In particular the presence of aggregates of actin microfilaments called stress fibres (SF). (b) A higher power view of a stress fibre (SF) in a myofibroblast. (c) A conventional fibroblast with its cytoplasm rich in rough endoplasmic reticulum. (d) A similar cell to that in (c); note the well developed Golgi system (G). $(a \times 20,000 ; b \times 36,000 ; c \times 15,000 ; d \times 13,000)$.

thin layers of silicone became distorted by traction lines as fibroblasts moved over them whereas macrophages hardly produced a ripple on the surface..$^{25}$ In other experiments, ${ }^{26}$ segments of tissue (explants) were placed on a collagenous gel and when the fibroblasts migrated out of the explants the collagen in the gel became distorted, the fibres were realigned parallel to the axis connecting adjacent explants and the gel contracted. Their observations were consistent with the idea that the migratory fibroblasts were exerting a physical pull on the substratum. This pull was not just a simple muscle-like contraction of the fibroblasts-instead of pulling the substratum by shortening their length the cells exert a shearing force by their own forward propulsion. The tractional force which develops is analo- gous to that exerted by a car's tyre on the road. Imagine a baby trying to crawl on a carpet which rests on a highly polished floor. As the baby tries to move the carpet starts to crumple and the more vigorous the baby's efforts the more ruffled and folded the carpet becomes.

The migratory fibroblast is continually altering its points of attachment to the loose temporary scaffold of clot, glycoprotein and collagen in the wound site. Traction results in the dragging in of these materials. Lewis ${ }^{27}$ compared the fibroblast drag to the action of sailors pulling ropes because they haul in the rope by a hand-over-hand action with the position of the hands on the rope continually altering. Time-lapse measurements of mobile retinal pigment epithelium (which have fibro- 
blast-like characteristics) pulling on collagen threads have shown a hauling in rate of around $2 \mu \mathrm{m}$ per minute. ${ }^{28}$ Our own data (Fig. 7) shows scleral fibroblasts can drag in strands of fibronectin at approximately $2 \mu \mathrm{m}$ per hour. These experiments are in no way comparable so the difference in rate is not meaningful. The two studies merely illustrate the 'reeling in' ability of mobile cells.

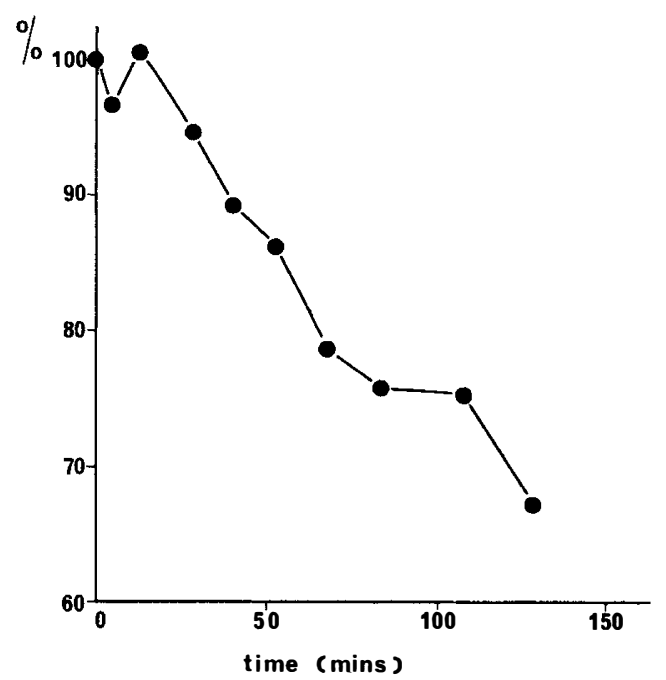

Fig. 7. Reeling in of 6 strands of fibronectin by scleral fibroblasts. The length of the strands decreased by over $30 \%$ of their initial length which equated to a reeling in rate of $2 \mu \mathrm{m}$ per hour.

If mobile fibroblasts, rather than the so called myofibroblasts, are responsible for generating the isotonic forces necessary to close wounds then what is the role of the elongated spindle shaped myofibroblasts? A clue to their role in scar tissue can be obtained from their ultrastructural features. These cells produce an extracellular matrix material called myofibroblast associated substance (MAS), they have junctions between adjacent cells, they have extensions sometimes referred to as microtendons and the actin microfilaments are organised into distinctive stress fibre aggregates (Fig. 6a and b). ${ }^{29}$ The presence of stress fibres provides a clue to the function of the myofibroblast because stress fibres are seen in abundance in cells in tissue culture and also in cells like vascular endothelium in vivo and are thought to be associated with sedentary behaviour. Cells with well developed stress fibres are considered to be strongly adherent to their substrata.

Kreis and Birchmeier ${ }^{30}$ showed that fibroblast stress fibres are contractile. However their function would seem to be to maintain tension so that cells with prominent stress fibres generate isometric rather than isotonic force. Thus the myofibroblast is like a cellular staple holding the contracted scar tissue in position until, later, it becomes cocooned in collagen and the tissue is stabilised. All the ultrastructural features described earlier e.g. junctions, MAS, microtendons are consistent with an isometric role. Therefore, we prefer to call these cells spindle fibroblasts, which is merely descriptive, rather than myofibroblasts, which assumes a function which may not be true.

The nest building activities of the Indian leaf ant have several parallels which help with the concepts we have outlined. These ants build a nest by bending a leaf over in half and then sealing the edges together to make a chamber. Initially the ants scurry all over the leaf and eventually bend the leaf over. As the edges come close together a number of ants hold one edge in their mandibles and the other by their back legs. These volunteers carry out the same function as the myofibroblast by holding the tension in the system (isometric). Unfortunately their fate is somewhat similar to the myofibroblasts because they end up cocooned, not in collagen but in silk.

Irrespective of the precise details, scar tissue contraction and the initial maintenance of the contracted state is cell dependent. Control of these contractile events requires us, if possible, to be able to influence the muscular and skeletal apparatus within the cytoplasm of the fibroblast. For example Trocinate, a powerful smooth muscle antagonist, was shown by Madden and co-workers ${ }^{31}$ to inhibit the normal contraction of the scar tissue which formed in full-thickness dorsal skin wounds. In a separate study of skin wound healing, contraction was impaired by the vinca alkaloids colchicine and vinblastin but surprisingly, not by cytochalasin B. ${ }^{32}$

As mentioned earlier, strips of scar tissue in an organ bath contract to electrical and pharmacological stimuli but interestingly the scar strips also were capable of drug-induced 
relaxation. One study on intravitreal scars demonstrated contraction to serotonin, angiotensin, bradykinin and relaxation with papaverine, cytochalasin B, diphenhydramine and diltiazem..$^{33}$

Another in vitro procedure for monitoring the contractile force generated by fibroblasts is the single cell contraction assay. For this, cultured fibroblasts are permeabilised with either glycerol ${ }^{34}$ or detergent ${ }^{35}$ and then exposed to ATP. The decrease in fibroblast surface area associated with the ATP-induced contraction can be measured manually or by image analysis. Under the circumstances of this assay, fibroblasts produce their optimum contraction with $0.1 \mathrm{mM}$ ATP and their response of $30 \%$ contraction is not far short of aortic smooth muscle cells subjected to the same evaluation (unpublished results from our own laboratory).

The single cell contraction assay provides an opportunity to evaluate drugs which might usefully counteract the isotonic and isometric forces generated by fibroblasts in scar tissue, and to investigate the fundamental mechanisms which influence the behaviour of contractile elements within fibroblasts. Not surprisingly, the contraction of fibroblasts is calcium dependent $;^{35}$ also cytochalasin B, trifluoperazine and alkaline phosphatase are effective blockers of ATP-induced contraction. ${ }^{36}$ In addition it has been shown that single cell fibroblast contraction can be supressed by preincubation with prostaglandin $E_{2}$, cholera toxin and cyclic AMP. ${ }^{36}$ It is known that elevated prostaglandin $E_{2}$ results in elevated cyclic AMP so that we are probably dealing with a common mechanism and it is hypothesised that contraction is inhibited because elevated cyclic AMP leads to the reduction of myosin ATPase and the consequent inhibition of cytoplasmic microfilament activity.

Whether or not many of the in vitro relaxants are as effective in vivo remains to be determined. We know that cytochalasin B which is so effective in vitro (see earlier) is disappointing when it comes to treating experimental wounds in rabbits. ${ }^{32}$ Trocinate has had encouraging effects on wounding but, in general the control of wound healing by modulating scar contraction remains an excit- ing but theoretical possibility. Developments in this area will be hampered whilst we still do not fully understand the underlying mechanisms involved in scar contraction.

\section{Synthesis}

The fibroblast produces the extracellular materials which are the structural components of the scar tissue at the site of a wound (Fig. 1). In wound healing the main components are collagens type 1 and 3 but, in addition, the fibroblast synthesises glycosaminoglycans, glycoproteins and elastic elements (Fig. 8). It is no wonder that the ultrastructural appearance of many of the fibroblasts during wound healing, is not as the myofibroblast described in the earlier section, but of a synthesising cell rich in rough endoplasmic reticulum (Fig. 6c and d). Usually the synthesising fibroblast has a well developed Golgi apparatus, many coated pits and vesicles, compact mitochondria with dense matrices and abundant lysosomes. It should be remembered that fibroblasts, as well as being proficient at synthesising extracellular materials, are equally adept at dissolving matrix substances by the release of enzymes such as collagenase. For that matter a process of remodelling continues within scar tissue long after the bulk of the scar has been established with localised dissolution and resynthesis of collagen taking place.

During wound healing the maximum production of glycoproteins precedes that of collagen. ${ }^{37}$ The principal glycoprotein formed at this time is fibronectin which adheres avidly to the fibrin clot. Since fibroblasts do not adhere particularly well to fibrin and fibronectin is the ideal substrate for fibroblasts (see earlier section) then it is more than probable that the insoluble fibrin-fibronectin complex serves as the temporary scaffold for the initial waves of fibroblast invasion. ${ }^{38}$ Fibronectin which is so abundant in an early wound is virtually absent from the mature scar.

Glycosaminoglycan formation peaks at about the same time as collagen production. These materials do not just fill the space between collagen fibres but have an intimate relationship with the collagen units. It has been shown that tissue which develops with a small diameter collagen fibril is rich in 


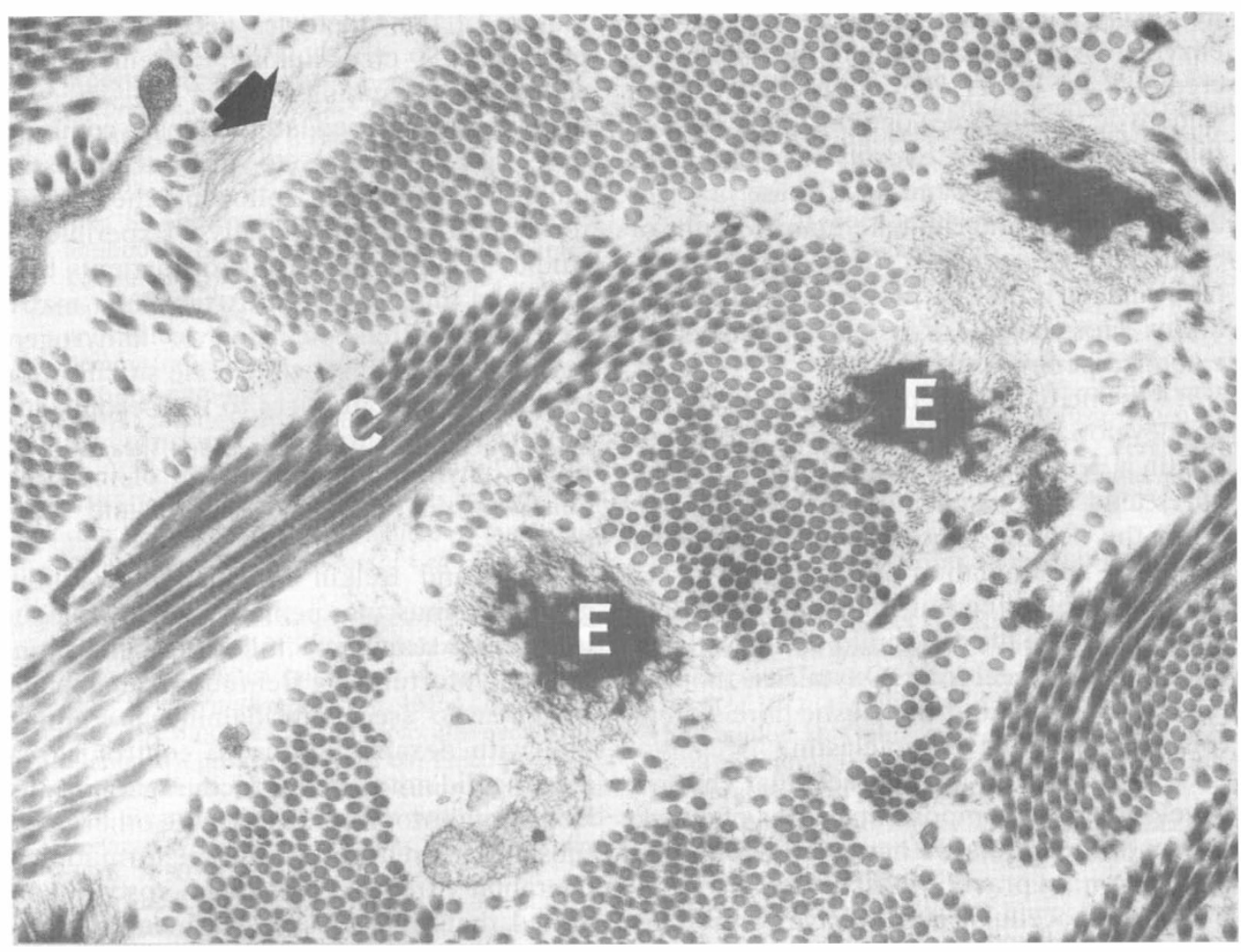

Fig. 8. Conjunctival scar tissue at the site of an old surgical wound. The transmission electron micrograph shows collagen bundles $(C)$, oxytalan (arrow) and elastic fibres $(E)(\times 18,000)$.

hyaluronic acid whereas those with a large diameter collagen fibril contain high concentrations of dermatan sulphate. The suggestion is that the growth of fibril diameter beyond $60 \mathrm{~nm}$ in diameter is inhibited by the presence of excess hyaluronic acid. ${ }^{39}$

Of the various forms of collagen (there are at least 12), types 1 and 3 are of particular interest in scar formation. Collagen production takes place in two stages, an intracellular and an extracellular stage. The backbone of all collagen molecules are triple stranded chains which form a regular helix. Each polypeptide strand (alpha chain) consists of approximately 1,000 amino acids and there are seven distinct types which have been identified. The polypeptide strands are produced on ribosomes and from there they pass into the lumina of rough endoplasmic reticulum. These pro-alpha-chains have, in addition to the alpha chain, a signal peptide needed for passing the chain into the rough endoplasmic reticulum and extension peptides for guiding triple helix formation. Alpha chains are rich in proline and glycine and some of these residues are hydroxylated in the endoplasmic reticulum before the chains form the triple helix of the procollagen molecules. The procollagen molecules are glycosylated and packaged with other macromolecules (extension peptides may be involved in the packaging process). The extension peptides are cleaved off the procollagen by peptidases during the subsequent secretion stage and this results in the formation of tropocollagen.

Outside the fibroblast the tropocollagen molecules align into microfibrils which subsequently bundle together to form collagen microfibrils. The tensile strength of collagen is enhanced by the many cross-links between the tropocollagen molecules in each microfibril. Cross-linkage starts by the oxidation to aldehyde of some of the terminal amino groups of lysines, hydrolysines or glycosylated 
hydroxylysine under the control of the enzyme lysyl oxidase. Then the aldehydes create links either by aldol condensation (aldehyde to aldehyde) or Schiff-base linkage (aldehyde to lysine, hydrolysine, etc). The aldol condensations and Schiff-base linkages develop slowly and can take many months or even years to complete. Indeed, the Schiffbase links are thought not be be stable and firmer cross-links are established over an extended period of time.

It was once considered that elastic fibres did not develop during wound healing. However, elastin is produced in wounds (Fig. 8) but the fibres tend to be small and they develop late on in the healing process. ${ }^{40}$ Little is known about the accumulation of elastic precursors following wounding but, interestingly, Alexander ${ }^{41}$ noted a massive build-up of oxytalan fibres in old corneal scars. Oxytalan is thought to be a component of the elastic fibre system consisting of fibrils but no elastin.

Clearly control of extracellular matrix development is as important an area of attack as any of the others we have outlined in this publication. In practice most attempts to control the extracellular matrix have centred on collagen since it is the main structural component. Prominent among the pharmacological agents used to control scarring are colchicine, Beta-aminoproprionitrile, penicillamine and to a lesser extent the enzyme collagenase (Table III). Colchicine has a direct effect on the fibroblasts and reduces their ability to secrete tropocollagen but also causes an increased outpouring of collagenase into the matrix. Beta-aminoproprionitrile and penicillamine are lathyrogens. The former inhibits lysyl oxidase and so prevents the for-

Table III Control of scar tissue with agents which act on collagen

\begin{tabular}{lc}
\hline Colchicine & $\begin{array}{c}\text { decreased collagen } \\
\text { synthesis } \\
\text { stimulated tissue } \\
\text { collagenase }\end{array}$ \\
$\begin{array}{c}\text { Beta Amino Proprio } \\
\text { Nitrile (BAPN) }\end{array}$ & $\begin{array}{c}\text { lathyrogen (inhibits lysyl } \\
\text { oxidase) } \\
\text { lathyrogen (chelates cross } \\
\text { Penicillamine }\end{array}$ \\
Collagenase & enzymic digestion \\
\hline
\end{tabular}

mation of the aldehydes necessary for tropocollagen cross-linking. Penicillamine chelates cross-linking sites. ${ }^{42-44}$

Peacock ${ }^{44}$ has used lathyrogens in combination with colchicine to prevent excessive build-up of collagen following the surgical removal of large keloids. Experimental studies in animals or trials on patients have indicated that control of extracellular matrix development by colchicine or lathyrogens may be of value in such diverse situations as treatment of alkali burns to the oesophagus, prevention of urethral strictures, tendon repair, cirrhosis, the reduction of intestinal adhesions in peritoneal healing and many others.

Weiss and Belkin ${ }^{45}$ showed that rabbits given intramuscular penicillamine developed less vitreal scar tissue following penetrating injury. Unfortunately Behrens-Baumann and Vogel $^{46}$ who used penicillamine in conjunction with dexamethasone to control vitreal scarring did not find any encouraging results. Beta-aminoproprionitrile, on the other hand, substantially reduced scar tissue formation in the rabbit vitreous. Electron microscopy confirmed that collagen was fragmented in the diminutive scars which formed after drug therapy. ${ }^{47}$ This inhibitor of collagen maturation has been used topically on filtering blebs following glaucoma surgery to reduce tensile strength and maintain drainage patency in difficult patients. ${ }^{48}$

\section{Conclusion}

As the complex life history of the fibroblast in wound healing becomes better understood an effective arsenal of drugs capable of controlling or killing fibroblasts has become available to us. Some are in clinical use, many are still the subjects of intensive investigation but we look forward to the time when we have an extensive and comprehensive panel of medications to control the development of ocular scarring.

This work has been supported by grants from the Wellcome Trust (Grant No. 15911/1.5), the Royal National Institute for the Blind, Fight for Sight, the TFC Frost Trust and the International Glaucoma Association. Secretarial assistance was provided by Miss S. M. Pavitt. 


\section{References}

${ }^{1}$ Oster GF, Murray JD, Harris AK: Mechanical aspects of mesenchymal morphogenesis. $J$ Embryol Exp Morph 1983, 78: 83-125.

${ }^{2}$ Hitchins CA, Grierson I, Rahi AHS: Contraction of scar tissue in the vitreous. Conn Tiss Res 1986, 15: $123-40$.

${ }^{3}$ Boyden S: The chemotactic effect of mixtures of antibody and antigen on polymorphonuclear leukocytes. J Exp Med 1962, 115: 453-66.

${ }^{4}$ Zigmond SJ and Hirsch JG: Leukocyte locomotion and chemotaxis: new methods for evaluation and demonstration of a cell-derived chemotactic factor. J Exp Med 1973, 137: 387-410.

${ }^{5}$ Albini A, Adelmann-Grill BC, Muller PK: Fibroblast chemotaxis. Collagen Rel Res 1985, 5: 28396.

${ }^{6}$ Ehrlich HP and Wyler DJ: Fibroblast contraction of collagen lattices in vitro: inhibition by chronic inflammatory cell mediators. J Cell Physiol 1983, 116: $345-51$.

${ }^{7}$ Lemor M, de Bustros S, Glaser BM: Low-dose colchicine inhibits astrocyte, fibroblast and retinal pigment epithelial cell migration and proliferation. Arch Ophthalmol 1986, 104: 1223-5.

${ }^{8}$ Pardee AB: Biochemical and molecular events regulating cell proliferation. J Path 1986, 149: 1-2.

${ }^{9}$ Freundlich B, Bomalaski JS, Neilson E, Jimenez SA: Regulation of fibroblast proliferation and collagen synthesis by cytokines. Immunol Today 1986, 7: 303-7.

${ }^{10}$ Ross R and Odland G: Human wound repair. II. Inflammatory cells, epithelial-mesenchymal interrelations and fibrogenesis. J Cell Biol 1968, 39: $152-68$.

${ }^{11}$ Hitchins CA and Grierson I: Experimental scar membranes in the rabbit's vitreous. An autoradiographic and quantitative morphological study. Acta Ophthalmol 1985, 63: 557-66.

12 Blumenkranz MS, Claflin A, Hajek AS: Selection of therapeutic agents for intraocular proliferative disease. Arch Ophthalmol 1984, 102: 598-604.

${ }^{13}$ Topol BM, Lewis VL, Benveniste K: The use of antihistamine to retard the growth of fibroblasts derived from human skin, scar and keloid. Plast Rec Surg 1981, 68: 227-32.

${ }^{14}$ Gressel MG, Parrish RK, Folberg R: 5-Fluorouracil and glaucoma filtering surgery: 1 . an animal model. Ophthalmol 1984, 91: 378-83.

${ }^{15}$ Kay JS, Litin BS, Jones MA, Fryczkowski AW, Chvapil M, Herschler J: Delivery of antifibroblast agents as adjuncts to filtration surgery-part II: delivery of 5-fluorouracil and bleomycin in a collagen implant: pilot study in the rabbit. Ophthalmic Surg 1986, 17: 796-801.

${ }^{16}$ Heuer DK, Parrish RK, Gressel MG, Hodapp E, Desjardins DC, Skuta GL, Palmberg PF, Nevarez JA, Rockwood EJ: 5-fluorouracil and glaucoma filtering surgery. III. intermediate follow-up of a pilot study. Ophthalmol 1986, 93: 1537-46.

${ }^{17}$ Blumenkranz MS, Ophir A, Claflin AJ, Hajek A: Fluorouracil for the treatment of massive per- iretinal proliferation. Am J Ophthalmol 1982, 94: 458-67.

${ }^{18}$ Blumenkranz MS, Claflin A, Norton EWD: 5-fluorouracil: new applications in complicated retinal detachment for an established antimetabolite. Ophthalmol 1984, 91: 122-30.

19 Wiedemann P, Kirmani M, Santana M, Ryan SJ: Control of experimental massive periretinal proliferation by daunomycin: dose response relation. Graefe's Arch Clin Exp Ophthalmol 1983, 220: $233-5$.

${ }^{20}$ Kirmani M, Santana M, Sorgente N, Wiedemann P, Ryan SJ: Antiproliferative drugs in the treatment of experimental proliferative vitreoretinopathy. Control by daunomycin. Retina 1983, 3: 269-72.

${ }^{21}$ Diener E, Diner UE, Sinha A, Xie S, Vergidis R: Specific immunosuppression by immunotoxins containing daunomycin. Science 1986, 231: 14850.

22 Olsnes S: Directing toxins to cancer cells. Nature 1981, 290: 84 .

${ }^{23}$ Gabbiani G, Herschel BJ, Ryan GB, Statkov PR, Majno G: Granulation tissue as a contractile organ. A study of structure and function. $J$ Exp Med 1972, 135: 819-34.

${ }^{24}$ Montandon D, Gabbiani G, Ryan GB, Majno G: The contractile fibroblast. Its relevance to plastic surgery. Plast Reconstr Surg 1973, 52: 55-67.

${ }^{25}$ Harris AK, Wild P, Stopak D: Silicone rubber substrata: A new wrinkle in the study of cell location. Science 1980, 208: 177-9.

${ }^{26}$ Harris AK, Stopak D, Wild P: Fibroblast traction as a mechanism for collagen morphogenesis. Nature 1981, 290: 249-51.

${ }^{27}$ Lewis J: Morphogenesis by fibroblast traction. Nature 1984, 307: 413-4.

${ }^{28}$ Glaser BM, Cardin A, Biscoe B: Proliferative vitreoretinopathy. The mechanism of development of vitreoretinal traction. Ophthalmol 1987, 94: 327-32.

${ }^{29}$ Ryan GB, Cliff WJ, Gabbiani G, Irle C, Montadon D, Statkov PR, Majno G: Myofibroblasts in human granulation tissue. Human Path 1974, 5: 55-67.

${ }^{30}$ Kreis TE and Birchmeier W: Stress fiber sarcomeres of fibroblasts are contractile. Cell 1980, 22: 55561.

${ }^{31}$ Madden JW, Morton D, Peacock EE: Contraction of experimental wounds. I. Inhibiting wound contraction by using a topical smooth muscle antagonist. Surgery 1974, 76: 8-15.

32 Ehrlich HP, Grislis G, Hunt TK: Evidence for the involvement of microtubules in wound contraction. Am J Surg 1977, 133: 706-9.

${ }^{33}$ Kirmani $\mathrm{K}$ and Ryan SJ: In vitro measurement of contractile force of transvitreal membranes formed after penetrating ocular injury. Arch Ophthalmol 1985, 103: 107-10.

${ }^{34}$ Ehrlich HP, Griswold TR, Rajaratnam J: ATPinduced cell contraction with epidermolysis bullosa recessive and normal dermal fibroblasts. $J$ Invest Dermatol 1986, 86: 96-100. 
${ }^{35}$ Masuda H, Owaribe K, Hatano S: Contraction of trition-treated culture cells. A calcium-sensitive contractile model. Exp Cell Res 1983, 143: 79-90.

${ }^{36}$ Ehrlich HP, Rajaratnam JBM, Griswold TR: ATPinduced cell contraction in dermal fibroblasts: effect of cAMP and myosin light-chain kinase. $J$ Cell Physiol 1986, 128: 223-30.

${ }^{37}$ Dolynchuk KN and Bowness JM: The early metabolism of noncollagenous glycoproteins during wound healing. J Surg Res 1981, 31: 218-24.

38 Yamada KM: Cell surface interactions with extracellular materials. Ann Rev Biochem 1983, 52: 761-99.

${ }^{39}$ Parry DAD, Flint MH, Gillard GC, Craig AS: A role for glycosaminoglycans in the development of collagen fibrils. Febs Letters 1982, 149: 1-7.

${ }^{40}$ Bhangoo KS and Church JTC: Elastogenesis in healing wounds in bats. Plast Rec Surg 1976, 67: 46879.

${ }^{41}$ Alexander RA: Elastic and related fibres in the human cornea. 1980; M Phil thesis; University of London.

${ }^{42}$ Chvapil M, Peacock EE, Carlson EC, Blau S,
Steinbronn K, Morton D: Colchicine and wound healing. J Sug Res 1980, 28: 49-56.

${ }^{43}$ Arem AJ, Misiorowski R, Chvapil M: Effects of low-dose BAPN on wound healing. J Surg Res 1979, 27: 228-32.

44 Peacock EE: Control of wound healing and scar formation in surgical patients. Arch Surg 1981, 116: 1325-9.

${ }^{45}$ Weiss JF and Belkin M: The effect of penicillamine on posttraumatic vitreous proliferation. Am J Ophthalmol 1981, 92: 625-7.

${ }^{46}$ Behrens-Baumann W and Vogel M: Experimental study on drug therapy of 'tractional retinal detachment' after posterior penetrating eye injury in the rabbit. Graefe's Arch Clin Exp Ophthalmol 1986, 224: 513-9.

${ }^{47}$ Moorhead LC: Effects of beta-aminoproprionitrile after posterior penetrating injury in the rabbit. Am J Ophthalmol 1983, 95: 97-109.

${ }^{48}$ Moorhead LC, Stewart R, Kimbrough R, Smith J, Fowler BJ: Effects of topically-applied Betaaminoproprionitrile after glaucoma filtration surgery. Invest Ophthalmol Vis Sci 1984, 25: (Suppl): 44. 